$\underline{\text { Article }}$

\title{
Design and Construction of an on-line SPE-SFE-CGC System
}

\author{
Jair S. S. Pinto, Esmeraldo A. Cappelaro and Fernando M. Lanças* \\ Instituto de Química de São Carlos, Universidade de São Paulo, C. P. 780, 13560-970 São Carlos - SP, Brazil
}

\begin{abstract}
Neste trabalho apresenta-se a construção de um sistema "on-line" de extração por fase sólidaextração com fluido supercrítico-cromatografia gasosa (SPE-SFE-CGC). O sistema "home-made" desenvolvido é de baixo custo, fácil construção e manutenção, tornando possível a análise de micropoluentes em amostras líquidas, tais como água, numa fração do tempo gasto pelos métodos tradicionais.
\end{abstract}

The construction of an on-line SPE-SFE-CGC system is described. The home-made system is of low cost and of easy construction and maintenance, making possible the analysis of organic micropollutants in liquid samples such as water in a fraction of the time spent using traditional methods.

Keywords: hyphenated systems, coupled systems, solid phase extraction, supercritical fluid extraction, gas chromatography

\section{Introduction}

In the last years, considerable effort has been spent to improve the speed and resolution of analyses and in the development of the instrumentation, data treatment and computer software for automation and system management. However, the sample preparation step, in many cases, is still performed by means of slow extraction techniques, such as the Soxhlet ${ }^{1}$.

Majors ${ }^{1}$ highlights that analysts spend $2 / 3$ of their time preparing samples; in the same study it is verified that $30 \%$ of the mistakes are due to the sample preparation step and $20 \%$ are due to the analysts. Therefore, improving and automating the sample preparation step can reduce errors by ca. $50 \%$.

Considering that one of the objectives of sample preparation is to extract the analytes of interest into a concentrated form, the search for modern procedures that improve its speed, precision and accuracy is easily understood. The procedure or the preparation technique must be easy, of low cost and safe.

For most important and complex environmental samples, including soils, water and food, simple analytical procedures are not satisfactory for clean-up due to weak selectivity and the presence of a large number of co-extractives, because the interferences frequently possess similar solubility properties to the analytes of interest.

Liquid-liquid extraction (LLE) is extensively used as a sample preparation approach. This technique uses the partition of the analyte among two non-miscible phases. The selectivity of LLE depends on the choice of the solvent and on the nature of the matrices ( $\mathrm{pH}$, ionic forces, etc.). In spite of being extensively used, LLE presents countless disadvantages, including the formation of foams, lack of automated instrumentation, long analysis time and cost of organic solvent disposal ${ }^{2}$.

Hirschfeld ${ }^{3}$ defined hyphenated instruments as "one in which both instruments are automated together as a single integrated unit via a hardware interface... whose function is to reconcile the often extremely contradictory output limitations of one instrument and the input limitations of the other". An on-line coupled system involving two established techniques limits both instruments to operate in conditions that are compatible one with the other ${ }^{4}$.

Supercritical fluid extraction $(\mathrm{SFE})^{5}$ and solid phase extraction (SPE) ${ }^{6-8}$ are possible alternatives to traditional extraction methods. Both techniques are used independently for clean-up or concentration of the analytes before the analysis. SFE is an excellent method for extracting organic compounds from solid sample matrices such as soil, while SPE is used mainly for diluted liquid samples.

The coupling of the two techniques (SFE-SPE) is an ideal method for the quantitative transfer of analytes trapped on SPE sorbent to the gas chromatographic column ${ }^{9}$. Since carbon dioxide is a gas at room temperature it is an ideal solvent for this interface.

The choice of the analytical system for the coupled technique ${ }^{4}$ should be based on the chromatographic technique more convenient for the extracted sample.

Typical SFE-CGC applications ${ }^{10-13}$ include those 
involving organic compounds adsorbed on solid matrices, because they eliminate the traditional extraction procedures and fractionation, that are the slowest steps in an analysis. The traditional methods can take days while coupled SFECGC is usually accomplished in one hour with excellent efficiency.

Coupled tendencies in chromatography have been driving it to automated analyses, incorporating on-line sample preparation in the final analytical procedure. Several advantages are obtained using on-line coupled techniques when compared with the equivalent off-line systems.

Off-line methods are slow and susceptible to solute losses and contamination. The coupled systems make possible a decrease of the detection limits, with improvement in the quantification, and the use of valves for automation results in faster and more reproducible analyses $^{14-21}$.

In the present work the objective was to build an online coupled SPE-SFE-CGC system using home-made SPE and SFE systems and a conventional gas chromatograph with PID detector.

\section{Experimental}

\section{Reagents}

Methanol (HPLC grade, Mallinckodt Chemical), dichloromethane (P.A. grade, Mallinckodt Chemical), naphthalene, fluorene, phenanthrene and anthracene (99\% purity, Chem Service) were used as received.

\section{Preparation of the standard solution}

Standard solutions $\left(100 \mathrm{mg} \mathrm{L}^{-1}\right)$ of selected Polynuclear Aromatic Hydrocarbons, PAHs, were prepared in methanol with the help of an ultrasonic bath, $40 \mathrm{~W}$ (Thornton-Inpec Eletrônica S/A) and diluted until the required volume. The solutions were stored at $4^{\circ} \mathrm{C}$.

Water was purified in a Milli-Q Plus system (Millipore) and used to prepare the working solutions $\left(5 \mathrm{mg} \mathrm{L}^{-1}\right)$.

\section{Construction of the on-line SPE-SFE-CGC system}

The complete system, as shown in Figure 1, can be divided into three independent modules (SPE, SFE and CGC) that could act coupled (SPE-SFE, SFE-CGC and SPE-SFE-CGC) or independently (CGC, SPE and SFE), that is, if it is necessary to use only the CGC module there would be no problem, the same happening with SPE and SFE.

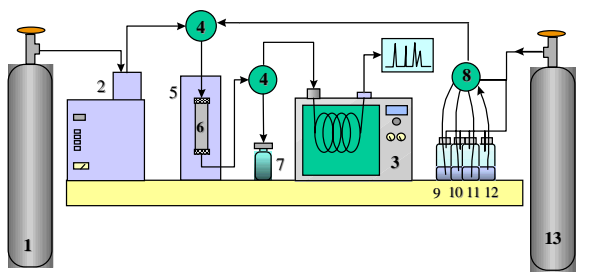

Figure 1. Schematic diagram of the developed on-line SPE-SFE-CGC system. 1. Carbon dioxide; 2. high pressure syringe pump; 3 . gas chromatograph; 4. three port valves; 5 . oven; 6 . extraction cell; 7. waste; 8. 10 port valve; 9-10. conditioning solvents; 11 . washing solvent; 12 . sample; 13. nitrogen.

\section{CGC Module}

Constituted of a SRI 8610 gas chromatograph, with two detectors (PID-FID) in series and a fused silica capillary column coated with $95 \%$ methyl $5 \%$ phenylpolysiloxane $(22 \mathrm{~m} \times 0.53 \mathrm{~mm} \times 1.4 \mathrm{~mm})$, interfaced with a PC computer using PEAKSIMPLER III software from SRI. Hydrogen was used as carrier gas at an average linear velocity of $26.2 \mathrm{~cm} \mathrm{~s}^{-1}\left(40^{\circ} \mathrm{C}\right)$ and the following temperature programming: $40^{\circ} \mathrm{C}$ for $20 \mathrm{~min}$, increased at $10^{\circ} \mathrm{C} \mathrm{min}^{-1}$ to $190^{\circ} \mathrm{C}$, held for $10 \mathrm{~min}$ and then at $10^{\circ} \mathrm{C} \mathrm{m^{-1 }}$ to $240^{\circ} \mathrm{C}$. Detection was done using a photo-ionization detector (PID) in most analysis.

\section{SFE Module}

Constituted of a high pressure VARIAN 8500 syringe pump, with refrigerated head, capable of pressurizing carbon dioxide at up to $600 \mathrm{~atm}$.

\section{SPE Module}

Projected and built in house, this module adapts to both small and large sample volumes; nitrogen is used to pressurize the flasks containing the solvents and the sample. A home-made 10 port valve is used for the selection of the solvents, conditioning of the solid phase, or for sample loading. After sample introduction, the SPE cartridge is dried for $30 \mathrm{~min}$ using one of the ports of the valve connected to a nitrogen supply.

\section{Interfaces}

\section{SFE-CGC}

The interface used for coupling the SFE module to the CGC instrument was based on the factory-installed oncolumn injector already fitted into the CGC instrument (Figure 2). The restrictor $(30 \mathrm{~cm} \times 25 \mu \mathrm{m})$ from the extraction cell is inserted directly into the capillary column through the standard on-column injector. The extracted 
components are directly deposited into the column, which is maintained cold with a cryogenic module using liquid carbon dioxide placed onto the first $10 \mathrm{~cm}$ of the capillary column immediately after the end of the restrictor. This will trap the analytes in the beginning of the column before the chromatographic run is started. The projected device consists of two concentric copper tubes (9/16" and 1/8") welded at their ends, with the carbon dioxide entering perpendicularly to the chromatographic column that is fitted inside the smaller 1/8" upper tube (item 6 Figure 2).

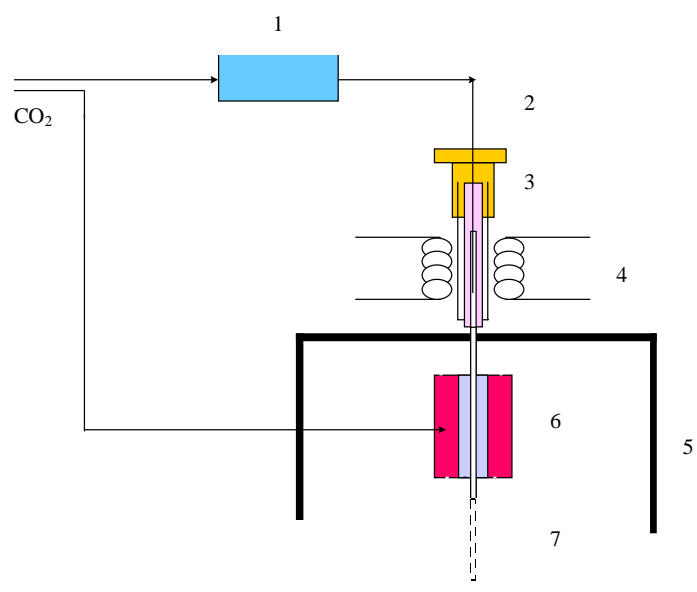

Figure 2. Interface for the on-line SFE-CGC coupling. 1. extraction cell; 2. fused silica restrictor ( $25 \mu \mathrm{m}$ i.d.x $30 \mathrm{~cm}$ length); 3 . on-column injector; 4. heater; 5 . oven; 6 . cryogenic module; 7 . column.

\section{SPE-SFE}

This interface was based on two three port $\mathrm{C} 3 \mathrm{~W}$ valves (VALCO), whose function is to select each SPE step; control the fractions sent to waste; and transfer the SFE extracted analyte to the capillary column.

\section{SPE-SFE-CGC Analyses}

The analyses were accomplished using $100 \mathrm{~mL}$ of water fortified with selected PAH. Initially the 316 stainless-steel cell (4 cm x $0.46 \mathrm{~cm}$ d.i.) packed with $0.25 \mathrm{~g}$ of $35-75$ mesh C18 (Alltech Associates Inc.) was conditioned with the passage of $5 \mathrm{~mL}$ dichloromethane (Figure 1), $5 \mathrm{~mL}$ methanol, $5 \mathrm{~mL}$ of water Milli-Q. The first 3 port valve is placed in the SPE position and the second valve in the discard position. After the sample loading step $(100 \mathrm{~mL})$ the extraction cell is dried with nitrogen for 30 minutes. The 3 port valves are then switched to the SFE (valve 1) and CGC (valve 2) positions thus allowing the transfer of the analytes to the CGC injector using a cryogenic system to trap the analytes into the first section of the capillary column. The conditions used for the supercritical fluid extraction (SFE) are displayed in Table 1.
Table 1. SFE operational conditions.

\begin{tabular}{lr}
\hline Extraction cell temperature $\left({ }^{\circ} \mathrm{C}\right)$ & $60-100$ \\
Restrictor temperature $\left({ }^{\circ} \mathrm{C}\right)$ & 60 \\
Oven temperature $\left({ }^{\circ} \mathrm{C}\right)$ & $20-25$ \\
TRAP temperature $\left({ }^{\circ} \mathrm{C}\right)$ & 0 \\
Extraction time $(\mathrm{min})$, static mode & 5 \\
Extraction time $(\mathrm{min})$, dynamic mode & $20-30$ \\
Carbon dioxide pressure (bar) & $275-300$ \\
\hline
\end{tabular}

At the end of the SFE step, the liquid carbon dioxide valve is closed, and the gas chromatographic run begins.

\section{Results and Discussion}

The coupled system developed and described in this work (Figures 1 and 2) is versatile and easy to handle, with the possibility of using extraction cells of several sizes; several solvents can be used for the conditioning and washing steps of the solid phase, besides the possibility of operating the SFE module in both static and dynamic extraction modes. The system allows the use of the same extraction cell for both SPE and SFE steps.

This coupled system possesses the advantage of being of low cost and of easy construction.

The chromatographic profiles obtained by CGC-PID of a standard PAH mixture and of two water sample spiked with four selected PAHs, analyzed by the coupled SPE-SFECGC system, are shown in Figures 3 and 4. It was verified that the cryogenic system was very effective to trap the analytes and the chromatograms obtained by both the direct injection of the sample onto the CGC system and by using the proposed SPE-SFE-CGC system are very similar.

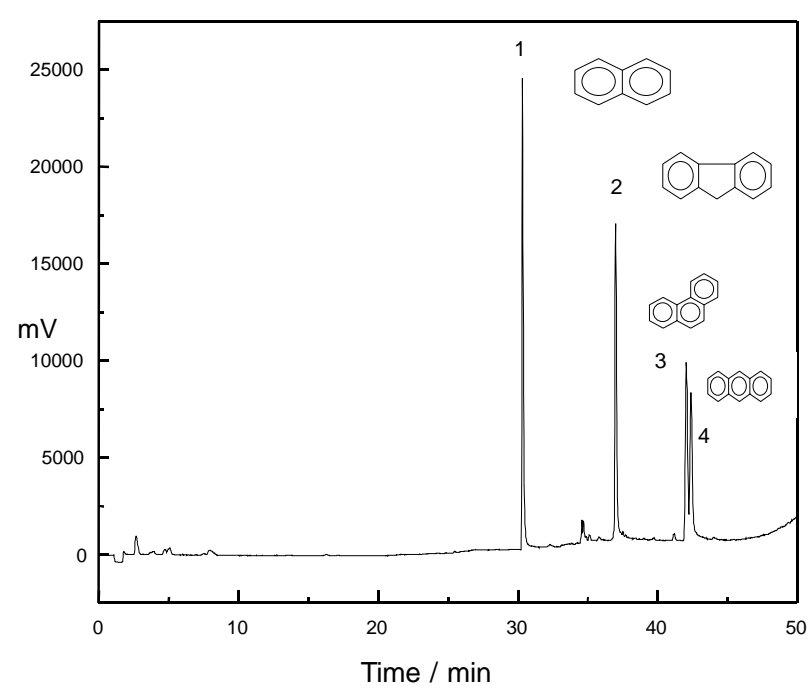

Figure 3. CGC-PID chromatogram of a PAH mixture using on-column injection. 1. Naphtalene; 2. fluorene; 3. phenanthrene; 4. anthracene. 


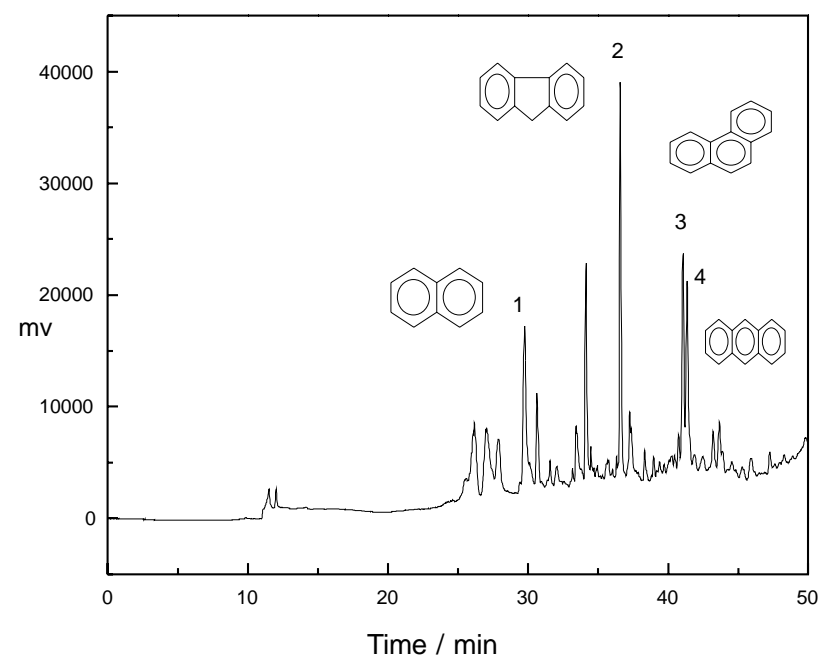

Figure 4. SPE-SFE-CGC chromatogram of a water sample spiked with a PAH mixture. Conditions: extraction temperature was $100^{\circ} \mathrm{C}$ during static and dynamic period ( $25 \mathrm{~min}$ and $300 \mathrm{bar}$ ). Peak identifications are the same as in Figure 3.

\section{Conclusion}

The results obtained demonstrate the viability of the on-line coupled SPE-SFE-CGC system for the analysis of micropollutants in liquid samples such as water in a fraction of the time usually spent using traditional methods. While the same analysis takes $3 \mathrm{~h}$ using the off-line approach, it can be performed in just $1 \mathrm{~h}$ using the proposed system. The system is of relatively low cost, and of easy construction, operation and maintenance.

The system can work in other coupled options, such as SPE-SFE and SFE-CGC, as well as in the SPE, SFE or CGC modes, independently.

\section{Acknowledgements}

The authors thank FAPESP (Proc. No. 1996/9269-5) and CNPq (Proc. No. 136357/96-2) for financial support, and the mechanical shop team of the IQSC USP-São Carlos for the construction of the components of the coupled SPESFE-CGC system.

\section{References}

1. Majors, R. E. LC-GC 1991, 9, 16.

2. Johnson, W. E.; Fendinger, N. J.; Plimmer, J. R. Anal. Chem. 1991, 63, 1510.

3. Hirschfeld, T. Anal. Chem. 1980, 52, 297A.

4. Davies, I. L.; Raynor, M. W.; Kithinji, J. P.; Bartle, K. D.; Williams, P. T.; Andrews, G. E. Anal. Chem. 1988, 60, 683A.

5. King, J. W. J. Chromatogr. Sci. 1989, 21, 355.

6. Liska, I.; Krupcik, J.; Leclercq, P. A. J. High Resolut. Chromatogr. 1989, 12, 577.

7. Bouvier, E. S. P.; Majors, R. E. $L C-G C$ 1995, 13, 852.

8. Majors, R. E. $L C-G C$ 1986, 4, 972.

9. Slack, G.; McNair, H. M.; Hawthorne, S. B.; Miller, D. J. J. High Resolut. Chromatogr. 1993, 16, 473.

10. Hawthorne, S. B.; Miller, D. J.; Krieger, M. S. J. Chromatogr. Sci., 1989, 27, 347.

11. Raymer, J. H.; Velez, G. R. J. Chromatogr. Sci. 1991, 29, 467.

12. Hawthorne, S. B.; Miller, D. J.; Langenfeld, J. J. J. Chromatogr. Sci. 1990, 28, 2

13. Levy, J. M.; Rosselli, A. T. Chromatographia 1989, 28, 606.

14. Hatonen, K., Riekkola, M-L. J. Chromatogr.B: Biomed. Sci. Appl. 1996, 676, 45.

15. Bernal J. L.; Nozal, M. J.; Toribio L.; Serna, M. L.; Borrull, F., Marcé, R. M.; Pocurull, E. J. Chromatogr. A 1997, 778, 321.

16. Suto, K.; Ito, Y.; Sagara, K.; Itokawa, H. J. Chromatogr. A 1997, 786, 366.

17. Chuang, J. C.; Pollard, M. A.; Misita, M.; Van Emon, J. M. Anal. Chimica Acta. 1999, 399, 135.

18. Li, J. Chemom. Intellig. Labor. Systems 1999, 45, 385.

19. Lesellier, E. Analusis 1999, 27, 363

20. Barman, B. N.; Cebolla, V. L.; Membrado, L. Crit. Rev. Anal. Chem. 2000, 30, 75.

21. Baiulescu, G. E. Anal. Lett. 2000, 33, 571.

22. Moret, S.; Conte, L. S. J. Chromatogr. A, 2000, $882,245$.

Received: October 29, 1999

Published on the web: February 19, 2001

FAPESP helped in meeting the publication costs of this article. 